\title{
KIẾN THỨC, THÁl Độ, THỰC HÀNH VỀ AN TOÀN THỰC PHẨM CỦA NGỪ̛̛I KINH DOANH THỨC ĂN ĐƯờNG PHỐ TẠI NộI THÀNH THÀNH PHỐ KON TUM NĂM 2018
}

\author{
Nguyễn Thị Thu Giang ${ }^{2 *}$, Lê Trí Khải ${ }^{1}$, Hoàng Chí Trung ${ }^{2}$ \\ Lưu Quốc Toản ${ }^{3}$, Hoàng Minh Tri
}

${ }^{1}$ Sở Y tế tỉnh Kon Tum

${ }^{2}$ Chi cục An toàn vệ sinh thực phẩm tỉnh Kon Tum

${ }^{3}$ Trường Đại học Y tế công cộng

(Ngày đến tòa soạn: 30/6/2019; Ngày sưa bài sau phản biện: 8/9/2019;

Ngày chấp nhận đăng: 16/9/2019)

\section{Tóm tắt}

Nghiên cứu này nhằm đánh giá kiến thức, thái độ, thực hành về an toàn thực phẩm của người kinh doanh thức ăn đường phố tại nội thành thành phố Kon Tum năm 2018 một cách khoa học, làm cơ sở xây dựng kế hoạch kiểm soát an toàn thực phẩm thức ăn đường phố và bảo vệ sức khỏe cho người tiêu dùng. Đối tượng nghiên cứu là 160 người kinh doanh tại 160 cơ sở kinh doanh thức ăn đường phố. Thời gian nghiên cứu từ tháng 11/2017 đến tháng 6/2018. Thiết kế nghiên cứu mô tả cắt ngang có phân tích. Thu thập thông tin bằng cách phỏng vấn trực tiếp kết hợp quan sát. Kết quả tỷ lệ người kinh doanh có kiến thức về an toàn thực phẩm đúng là $64,4 \%$, thái độ về an toàn thực phẩm tích cực là $45,6 \%$ và thực hành về an toàn thực phẩm đúng là $33,1 \%$. Các yếu tố có liên quan đến kiến thức là giám sát của chính quyền địa phương, việc kiểm tra và phản ứng của người kinh doanh $(\mathrm{P}<0,05)$. Các yếu tố có liên quan đến thái độ là việc kiểm tra và kiến thức $(\mathrm{P}<0,05)$. Các yếu tố có liên quan đến thực hành là giám sát của chính quyền địa phương, việc kiểm tra và kiến thức $(\mathrm{P}<0,05)$.

Tù khóa: An toàn thực phẩm, thức ăn đường phố, kiến thức, thái độ, thực hành, Kon Tum.

\section{1. ĐẠTT VẤN ĐỀ}

Theo Luật ATTP 2010, thức ăn đường phố (TĂĐP) là thực phẩm được chế biến (CB) dùng để ăn, uống ngay, trong thực tế được thực hiện thông qua hình thức bán rong, bày bán trên đường phố, nơi công cộng hoặc những nơi tương tự [8]. Thức ăn đường phố cũng là văn hóa của ẩm thực Việt. Tuy nhiên, nhiều vấn đề về an toàn thực phẩm (ATTP) vẫn là những thách thức đối với cơ quan quản lý, người tiêu dùng và người kinh doanh $(\mathrm{KD}) \mathrm{TĂ} Đ P$ [6]. Hiện nay, tại nhiều địa phương trong đó có tỉnh Kon Tum, ATTP TĂĐP vẫn chưa được kiểm soát [1].

Nội thành thành phố Kon Tum là sáu phường có các tuyến đường chính, kinh tế và du lịch có xu hướng phát triển, người dân sống đông đúc. Tại đây, TĂĐP chiếm khoảng 72,4\% so với 15 xã, phường còn lại của thành phố Kon Tum. Khảo sát sơ bộ tại sáu phường nội thành của thành phố Kon Tum cho thấy 26,7\% (8/30) người KDTĂĐP đạt trên trung bình các tiêu chí về ATTP và không có cơ sở nào đạt cả $100 \%$ các tiêu chí. Từ thực trạng này, chúng tôi cho rằng cần có một nghiên cứu về kiến thức, thái độ, thực hành về ATTP của người KDTĂĐP tại nội thành Kon Tum để làm cơ sở xây dựng các kế hoạch nhằm kiểm soát ATTP TĂĐP và bảo vệ sức khỏe cho người tiêu dùng.

\footnotetext{
* Điện thoại: 0935911415

Email: thugiangkt2009@gmail.com
} 
Do vậy, chúng tôi tiến hành đề tài "Kiến thức, thái độ, thực hành về an toàn thực phẩm của người kinh doanh thức ăn đường phố tại nội thành thành phố Kon Tum năm 2018" với hai mục tiêu: mô tả kiến thức, thái độ, thực hành về ATTP và xác định một số yếu tố liên quan đến kiến thức, thái độ, thực hành về ATTP của người KDTĂĐP tại nội thành thành phố Kon Tum năm 2018.

\section{PHƯO'NG PHÁP NGHIÊN CÚUU}

\section{1. Đối tượng nghiên cứu}

- Người kinh doanh thức ăn đường phố.

\subsection{Thiết kế nghiên cứu}

- Mô tả cắt ngang có phân tích.

\subsection{Thời gian và địa điểm nghiên cứu}

\subsubsection{Thời gian nghiên cưu}

- Từ tháng 11/2017 đến tháng 6/2018, trong đó thời gian thu thập số liệu tại thực địa tháng $4 / 2018$.

\subsection{2. Địa điểm nghiên cúu}

- Tại sáu phường nội thành của thành phố Kon Tum, bao gồm: Duy Tân, Quang Trung, Quyết Thắng, Thắng Lợi, Thống Nhất và Trường Chinh.

\subsection{Cỡ mẫu và cách chọn mẫu}

\subsubsection{Cõ̃ $m \tilde{\hat{a} u}$}

Do quần thể rất nhỏ nên cỡ mẫu được tính dựa trên công thức tính cỡ mẫu cho một quần thể hữu hạn

$$
n=\frac{N z^{2} p(1-p)}{d^{2}(N-1)+z^{2} p(1-p)}
$$

Trong đó:

- n: Cỡ mẫu nghiên cứu tối thiểu;

- N: Tổng số người KDTĂĐP của 06 phường, $\mathrm{N}=323$;

- $\mathrm{p}=$ 0,271 theo nghiên cứu của Trần Thị Hồng Nhung (2017), có 27,1\% người KDTĂĐP thực hành đạt yêu cầu [7];

- d: độ chính xác, chọn $\mathrm{d}=0,05$;

- z: hệ số tin cậy, với $\alpha=0,05, Z(1-\alpha / 2)=1,96$. Theo công thức trên thì cỡ mẫu tối thiểu đưa vào nghiên cứu là 157 người làm tròn là 160 người.

\subsubsection{Cách chọn mẫu}

Chọn mẫu theo phương pháp chọn mẫu ngẫu nhiên hệ thống: lập khung mẫu là danh sách theo số thứ tự cơ sở kinh doanh TÂ円P tại nội thành Kon Tum (323 cơ sở). Tính hệ số mẫu k, với tổng số cơ sở kinh doanh TĂĐP tại nội thành Kon Tum là 323 cơ sở/cỡ mẫu tối thiểu 160 cơ sở, $\mathrm{k}=2,02$ chọn $\mathrm{k}=2$. Trên danh sách cơ sở kinh doanh TĂĐP tại nội thành Kon Tum chọn ngẫu nhiên một cơ sở đầu tiên có số thứ tự $\mathrm{i} \leq \mathrm{k}$, cơ sở kế tiếp có số thứ tự là: $(\mathrm{i}+\mathrm{k}),(\mathrm{i}+2 \mathrm{k}),(\mathrm{i}+3 \mathrm{k}), \ldots$ đến khi đủ 160 mẫu.

\subsection{Phương pháp thu thập số liệu}

Sử dụng bảng gồm 19 câu hỏi phỏng vấn kiến thức với tổng 42 đáp án trả lời đúng, 15 câu hỏi phỏng vấn thái độ cho điểm từ "Tiêu cực" (1) đến "Tích cực" (5), bảng kiểm quan sát 14 hành vi thực hành căn cứ vào Luật $\mathrm{ATTP}$. Tại mỗi cơ sở KDTĂĐP được chọn, khảo sát 01 người trực tiếp $\mathrm{CB}, \mathrm{KD}$ và đang làm việc tại cơ sở tại thời điểm nghiên cứu. Tại cơ sở nào được chọn, đối tượng nghiên cứu thuộc diện không hợp tác thì bỏ qua và chọn đối tượng khác có số thứ tự kế tiếp trong danh sách. 


\subsection{Phương pháp đánh giá}

Phần kiến thức có thang điểm từ 1 đến 42, kiến thức được đánh giá là "Đạt” khi phần kiến thức có tổng điểm $\geq 80 \%$ [4]. Phần thái độ có thang điểm từ 1 đến 5 , thái độ được đánh giá là "Tích cực" khi phần thái độ có số điểm trung bình $\geq 4$. Phần thực hành có thang điểm từ 1 đến 14 , thực hành được đánh giá là "Đạt" khi phần thực hành có tổng điểm $\geq 50 \%$ [5].

\subsection{Phương pháp xử lý số liệu}

Thông tin thu thập được nhập vào phần mềm Epidata 3.1, làm sạch và sau đó xử lý bằng phần mềm SPSS 18.0, các phương pháp phân tích thống kê mô tả phù hợp đã được sử dụng. Sử dụng kiểm định khi bình phương $\left(\chi^{2}\right)$ và tỷ số chênh $(\mathrm{OR})$ để xác định độ mạnh của sự kết hợp giữa các biến số và mối liên quan giữa các biến số quan tâm.

\section{KẾT QUẢ}

\subsection{Kiến thức, thái độ, thực hành về ATTP của đối tượng nghiên cứu}

\subsubsection{Kiến thức về ATTP của đối tượng nghiên cưu}

Phỏng vấn kiến thức của 160 người được chia làm 6 nhóm nội dung đánh giá gồm:

1. Đánh giá kiến thức ATTP về vệ sinh người chế biến.

2. Đánh giá kiến thức ATTP về nguồn nước chế biến, nước đá, nguyên liệu.

3. Đánh giá kiến thức ATTP về địa điểm, môi trường.

4. Đánh giá kiến thức cơ bản về ATTP.

5. Đánh giá kiến thức ATTP về chế biến, bảo quản.

6. Đánh giá kiến thức ATTP về các thủ tục hành chính.

Kết quả tổng hợp, phân tích và đánh giá cho thấy tỷ lệ người trực tiếp KDTĂĐP có kiến thức đạt về vệ sinh người chế biến là $100 \%$, về nguồn nước là $98,1 \%$, tuy nhiên về thủ tục hành chính chỉ đạt là 33,1\% (Hình 1).

Tỷ lệ kiến thức đúng (\%)

Đánh giá kiến thức ATTP về vệ sinh người chế biến

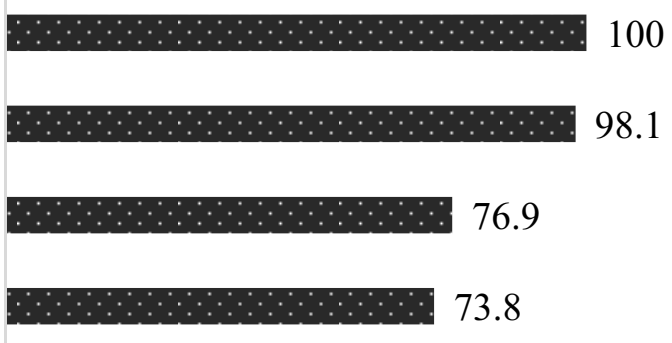

Đánh giá kiến thức ATTP về nguồn nước chế biến, nước đá, nguyên liệu

Đánh giá kiến thức ATTP về địa điểm, môi trường

Đánh giá kiến thức cơ bản về an toàn thực phẩm

Đánh giá kiến thức ATTP về chế biến, bảo quản

Đánh giá kiến thức ATTP về các thủ tục hành chính

Hình 1. Kiến thức về ATTP của đối tượng nghiên cưu (n=160)

\subsubsection{Thái độ về ATTP của đối tương nghiên cưu}

Phỏng vấn thái độ của 160 người được chia thành 5 nhóm nội dungđánh giá gồm:

1. Người bán hành mặc trang phục sạch sẽ, gọn gàng.

2. Đánh giá thái độ về vệ sinh dụng cụ, chế biến, bảo quản TĂĐP. 
3. Đánh giá thái độ về vệ sinh cơ sở, địa điểm môi trường kinh doanh TĂĐP.

4. Đánh giá thái độ về thực hiện các quy định hành chính đảm bảo TĂĐP.

5. Đánh giá thái độ về vệ sinh nguồn nước, nước đá, nguyên liệu thực phẩm.

Kết quả tổng hợp, phân tích và đánh giá cho thấy tỷ lệ người trực tiếp KDTĂĐP có thái độ tích cực về vệ sinh người chế biến là $98,8 \%$, tuy nhiên về vệ sinh nguồn nước, nước đá, nguyên liệu là thực phẩm chỉ đạt 14,4\% (Hình 2).

* Tỷ lệ thái độ tích cực (\%)

Người bán hàng mặc trang phục sạch sẽ, gọn gàng.

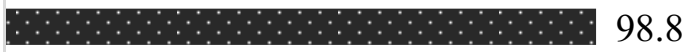

Đánh giá thái độ về vệ sinh dụng cụ, chế biến, bảo quản TĂĐP

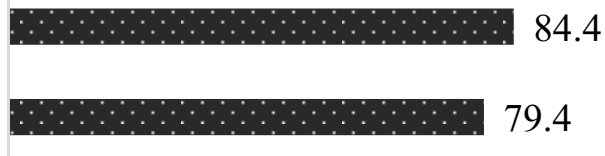

Đánh giá thái độ về vệ sinh cơ sở, địa điểm môi trường kinh doanh TĂĐP

Đánh giá thái độ về thực hiện các quy định hành chính đảm bảo ATTP

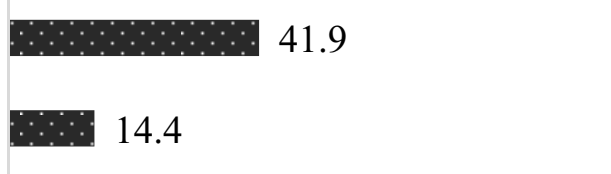

Đánh giá thái độ về vệ sinh nguồn nước, nước đá, nguyên liệu thực phẩm

Hinh 2. Thái độ về ATTP của đối tượng nghiên cưu $(n=160)$

\subsubsection{Thực hành về ATTP của đối tương nghiên cứu}

Qua quan sát thực hành của 160 người được chia thành 5 nhóm nội dung đánh giá gồm:

1. Đánh giá thực hành về vệ sinh con người.

2. Đánh giá thực hành về vệ sinh dụng cụ, chế biến, bảo quản thức ăn đường phố.

3. Đánh giá thực hành về vệ sinh nguồn nước, nước đá, nguyên liệu thực phẩm.

4. Đánh giá thực hành về vệ sinh cơ sở, địa điểm môi trường kinh doanh thức ăn đường phố.

5. Đánh giá thực hành về thực hiện các quy định hành chính đảm bảo ATTP.

Kết quả tổng hợp, phân tích và đánh giá cho thấy tỷ lệ người trực tiếp KDTĂĐP có thực hành đúng về vệ sinh con người là $99,4 \%$, tuy nhiên về thực hiện các quy định hành chính đảm bảo ATTP chỉ đạt $16,2 \%$.

- Tỷ lệ thực hành đúng (\%)

Đánh giá thực hành về vệ sinh con người

Đánh giá thực hành về vệ sinh dụng cụ, chế biến, bảo quản thức ăn đường phố

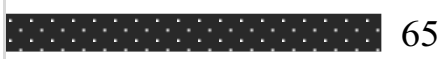

Đánh giá thực hành về vệ sinh nguồn nước, nước đá, nguyên liệu thực phẩm

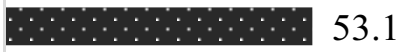

Đánh giá thực hành về vệ sinh cơ sở, địa điểm môi trường kinh doanh thức ăn đường phố

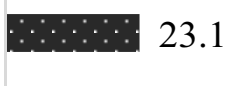

Đánh giá thực hành về thực hiện các quy định hành chính đảm bảo an toàn thực phẩm 


\subsection{4. Đánh giá chung về kiến thức, thái độ, thực hành ATTP của đối tượng nghiên cứu}

Tổng hợp đánh giá trên 03 nội dung gồm: kiến thức, thái độ, thực hành về ATTP của đối tượng nghiên cứu trên 160 người tham gia, kết quả cho thấy tỷ lệ người trực tiếp KDTĂĐP có kiến thức về ATTP đạt là $64,4 \%$, thái độ tích cực về ATTP là 45,6\% và thực hành đúng về ATTP là 33,1\% (Hình 4).

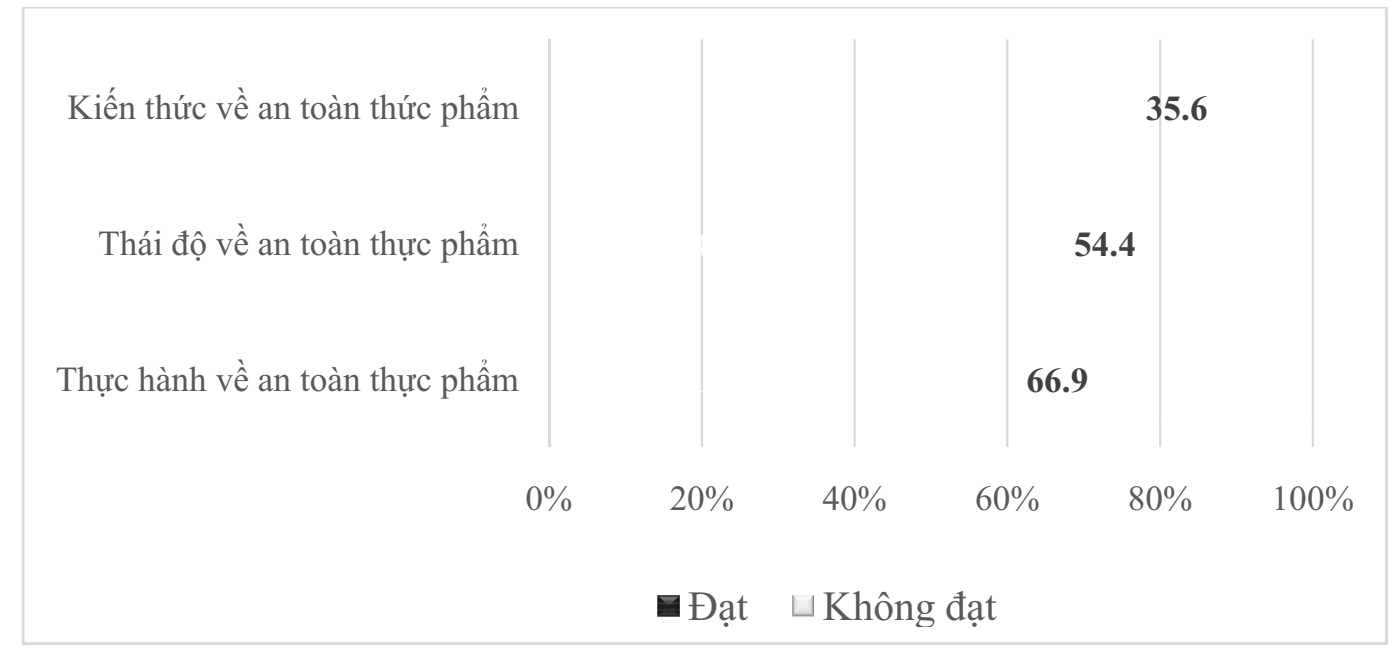

Hình 4. Kiến thức, thái độ, thực hành về ATTP của đối tượng nghiên cứu (n=160)

\subsection{Một số yếu tố liên quan đến kiến thức, thái độ, thực hành về ATTP của người KDTĂĐP}

\subsubsection{Yếu tố liên quan đến kiến thức về ATTP của người KDTĂĐP}

Phân tích đánh giá yếu tố liên quan đến kiến thức, kết quả tại bảng 1 cho thấy có mối liên quan giữa giám sát của chính quyền địa phương, kiểm tra ATTP với kiến thức về ATTP, sự khác biệt này có ý nghĩa thống kê với $\mathrm{P}<0,05$.

Bảng 1. Mối liên quan giữa thông tin của đối tượng nghiên cứu với kiến thức về ATTP $(n=160)$

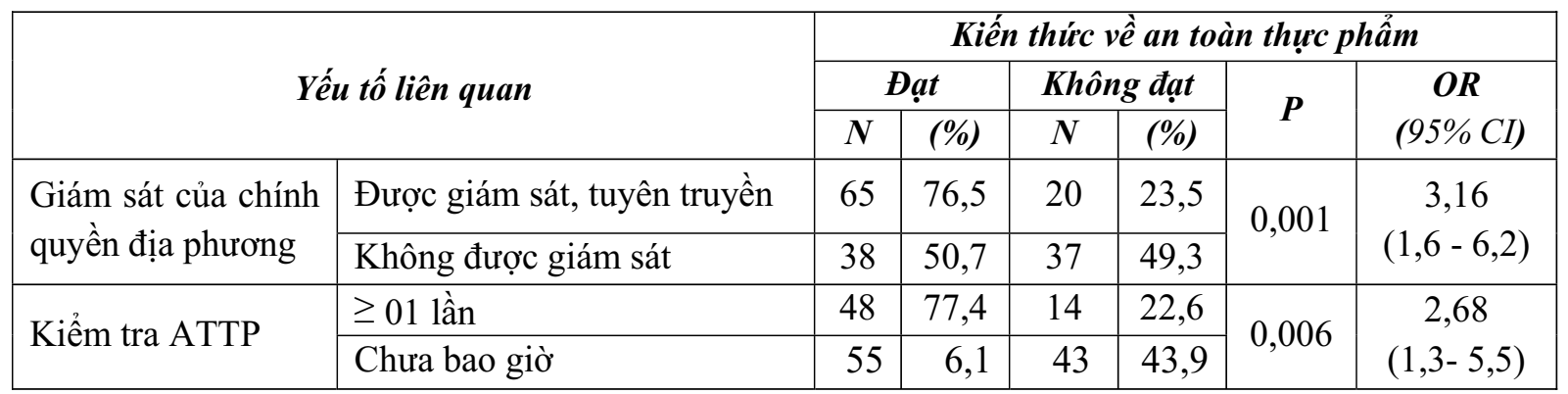

\subsubsection{Yếu tố liên quan đến thái độ về ATTP của người KDTĂĐP}

Phân tích đánh giá yếu tố liên quan đến thái độ, kết quả tại bảng 2 cho thấy có mối liên quan giữa kiểm tra ATTP, kiến thức về ATTP với thái độ về ATTP, sự khác biệt này có ý nghĩa thống kê với $\mathrm{P}<0,05$.

Bảng 2. Mối liên quan giữa kiểm tra, kiến thức với thái độ về ATTP (n=160)

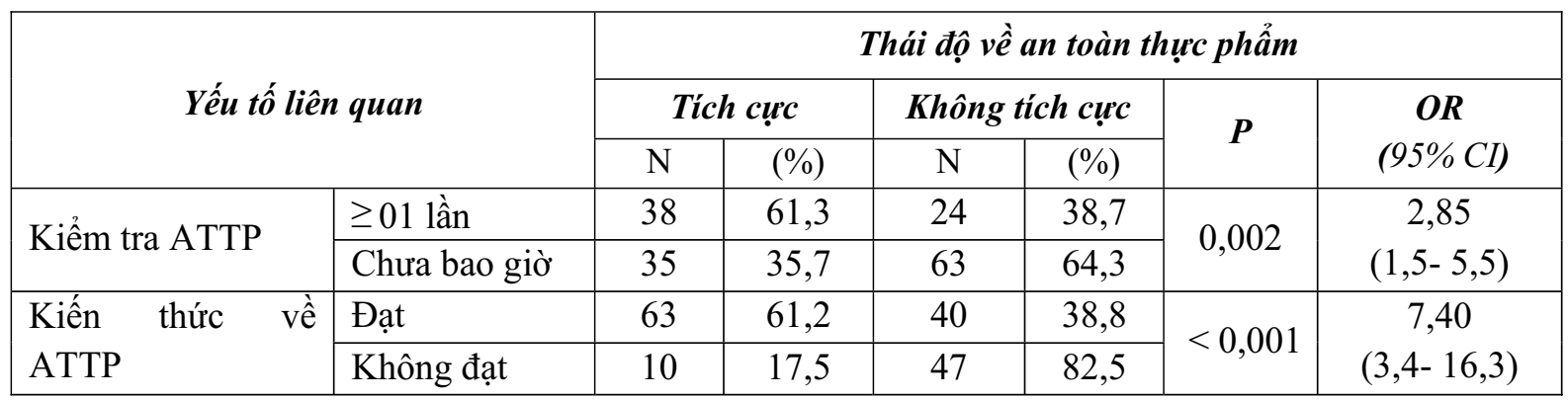




\subsubsection{Yếu tố liên quan đến thực hành về ATTP của người KDTĂĐP}

Phân tích đánh giá yếu tố liên quan đến thực hành, kết quả tại bảng 3 cho thấy có mối liên quan giữa kiểm tra ATTP, kiến thức về ATTP với thực hành về ATTP, sự khác biệt này có ý nghĩa thống kê với $\mathrm{P}<0,05$. Phân tích cũng cho thấy không có mối liên quan giữa thực hành về ATTP với thái độ về ATTP.

Bảng 3. Mối liên quan giữa kiểm tra, kiến thức, thái độ với thụcc hành về ATTP $(n=160)$

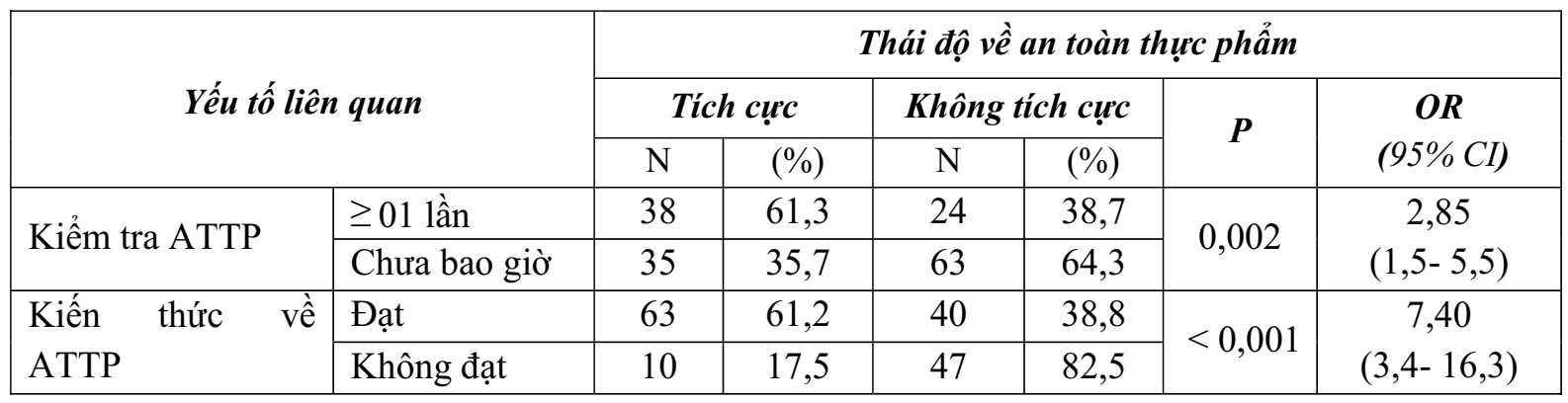

\section{BÀN LUẤN}

\subsection{Kiến thức, thái độ, thực hành về ATTP của người KDTĂĐP}

Qua nghiên cứu cho thấy, tỷ lệ người KD có kiến thức đạt về ATTP là 64,4\%, thấp hơn kết quả nghiên cứu của Hoàng Khánh Chi $(89,3 \%)$ [2]. Từ đó, cho thấy hiểu biết của đối tượng nghiên cứu về ATTP không cao, vì vậy việc tăng cường truyền thông, giáo dục kiến thức về ATTP TĂĐP là rất cần thiết.

Tỷ lệ người $\mathrm{KD}$ có thái độ tích cực về ATTP là 45,6\%, thấp hơn kết quả nghiên cứu của Hoàng Khánh Chi (61,7\%) [2]. Từ kết quả trên cho thấy, thái độ tích cực về ATTP của người KDTĂĐP còn thấp, vì vậy ngoài việc tăng cường công tác truyền thông về ATTP với đa dạng phương pháp, còn phải có các tác động của các yếu tố môi trường xung quanh.

Đánh giá thực hành về ATTP của người KDTĂĐP cho thấy tỷ lệ đạt là 33,1\%. Kết quả này thấp hơn kết quả nghiên cứu của Phan Thị Lành $(36,2 \%)$ [5]. Kết quả trên cho thấy, tỷ lệ người KDTĂĐP thực hành chung đạt về ATTP còn thấp.

\subsection{Các yếu tố liên quan đến kiến thức, thái độ, thực hành về ATTP của người KDTĂĐP}

Nghiên cứu cho thấy, người KD tại cơ sở được giám sát của chính quyền địa phương có kiến thức chung đạt cao gấp 3,2 lần so với người $\mathrm{KD}$ tại cơ sở chưa được giám sát của chính quyền địa phương, người $\mathrm{KD}$ tại cơ sở được kiểm tra có kiến thức chung đạt cao gấp 2,7 lần so với người $\mathrm{KD}$ tại cơ sở chưa được kiểm tra $(\mathrm{P}<0,05)$. Khi người $\mathrm{KD}$ được chính quyền địa phương giám sát, tuyên truyền hay kiểm tra ATTP thì sẽ giúp đỡ người KD có thêm kiến thức về $\mathrm{ATTP}$, về lâu dài sẽ trở thành kinh nghiệm khi chế biến thực phẩm nên tỷ lệ đạt kiến thức về ATTP sẽ cao hơn so với người KD không có giám sát của chính quyền địa phương hay không kiểm tra ATTP.

Người KD tại cơ sở được kiểm tra có thái độ chung tích cực cao gấp 2,9 lần so với người $\mathrm{KD}$ tại cơ sở chưa được kiểm tra, người $\mathrm{KD}$ kiến thức chung đạt có thái độ chung tích cực cao gấp 7,4 lần so với người $\mathrm{KD}$ kiến thức chung không đạt $(\mathrm{P}<0,05)$. Nghiên cứu của Lê Ngọc Hiệp $(2017)$ [3] cũng cho thấy có sự liên quan giữa kiến thức và thái độ. Có thể hiểu rằng khi người $\mathrm{KD}$ tiếp cận với đoàn kiểm tra ATTP sẽ được tuyên truyền nhiều hơn về mức độ trầm trọng của việc cung cấp thực phẩm không an toàn, được tư vấn hướng dẫn cụ thể hơn khi phát hiện vi phạm về ATTP và khi người $\mathrm{KD}$ có kiến thức đúng về $\mathrm{ATTP}$ sẽ suy nghĩ và có thái độ tích cực hơn. 
Người KD tại cơ sở được kiểm tra có thực hành chung đạt cao gấp 2,7 lần so với người KD tại cơ sở chưa được kiểm tra. Người $\mathrm{KD}$ có kiến thức chung đạt thì thực hành chung đạt cao gấp 5,8 lần so với người $\mathrm{KD}$ có kiến thức chung không đạt. Tuy nhiên, nghiên cứu cho thấy không có mối liên quan giữa thái độ và thực hành. Do đó, cần tăng cường tuyên truyền, hướng dẫn và kiểm tra vì khi được kiểm tra người $\mathrm{KD}$ có thêm kiến thức về những hành vi vi phạm và buộc phải khắc phục những hành vi đó nên sẽ thực hành tốt hơn.

Các thông tin khác như dân tộc, tuổi, trình độ học vấn của người KDTĂĐP, thời gian bán hàng trong ngày, địa điểm ăn, địa điểm bán không có mối liên quan đến kiến thức, thái độ, thực hành về ATTP. Các nghiên cứu trước đây về kiến thức, thái độ, thực hành của các đối tượng $\mathrm{KD}$ dịch vụ ăn uống, bếp ăn tập thể trên địa bàn tỉnh Kon Tum của Nguyễn Thị Thu Giang cũng cho kết quả tương tự.

\section{KẾT LUẬN}

Tỷ lệ người trực tiếp KDTĂĐP có kiến thức về ATTP đạt là 64,4\%, thái độ tích cực về ATTP là $45,6 \%$ và thực hành đúng về ATTP là $33,1 \%$. Những đối tượng KD được giám sát của chính quyền địa phương, được kiểm tra thì có kiến thức chung đạt cao hơn so với chưa được giám sát của chính quyền địa phương, chưa được kiểm tra. Người $\mathrm{KD}$ có kiến thức chung đạt, được kiểm tra thì có thái độ chung tích cực hơn và thực hành chung đạt cao hơn so với người $\mathrm{KD}$ có kiến thức chung không đạt, chưa được kiểm tra.

\section{TÀI LIỆU THAM KHẢO}

1. Bộ Y tế Việt Nam \& nhóm đối tác Y tế (2006), Báo cáo chung tổng quan ngành y tế năm 2015 - Tăng cường y tế cơ sở hướng tới bao phủ chăm sóc sức khoẻ toàn dân.

2. Hoàng Khánh Chi, Nhữ Văn Hùng \& Lê Văn Hữu (2013), "Kiến thức, thái độ, thực hành về an toàn thực phẩm và các yếu tố liên quan của người kinh doanh, chế biến thức ăn đường phố huyện Thanh Bình, tỉnh Đồng Tháp năm 2012", Tạp chí Y học thực hành, 4/2013 (866), tr. 111-114.

3. Lê Ngọc Hiệp (2017), "Kiến thức, thái độ, thực hành về vệ sinh an toàn thực phảm và một số yếu tố liên quan của người kinh doanh thức ăn đường phố tại thành phố Long Xuyên, tỉn An Giang năm 2014", Tạp chí Khoa học truờng Đại học An Giang, 13(1), tr. 68-78.

4. Phan Thị Lành (2017), "Kiến thức về an toàn thực phẩm của người chế biến chính ở các cơ sở kinh doanh thức ăn đường phố tại huyện Tân Hồng, tỉnh Đồng Tháp, năm 2016", Tạp chí Y hoc dư phòng, 27(6).

5. Phan Thị Lành (2017), "Thực hành về an toàn thực phẩm và một số yếu tố liên quan của người chế biến chính ở các cơ sở kinh doanh thức ăn đường phố tại huyện Tân Hồng, tỉnh Đồng Tháp, năm 2016", Tạp chí Y học dụ phòng, 27(7).

6. Dương Quế Nhu, Nguyễn Tri Nam Khang \& Nguyễn Thị Thảo Ly (2014), "Nét độc đáo của ẩm thực Việt Nam qua đánh giá của du khách quốc tế", Tạp chí Khoa học truờng Đại học Cần Tho, (30), tr. 51-59.

7. Trần Thị Hồng Nhung \& Nguyễn Hùng Long (2017), "Kiến thức, thực hành an toàn thực phẩm của cơ sở kinh doanh thức ăn đường phố tại quận Hai Bà Trưng, Hà Nội 2016", Tạp chi Y hoc dụ phòng, 3/2017(27).

8. Quốc hội (2010), Luật An toàn thực phẩm số 55/2010/QH12, ngày 17/6/2010. 


\title{
Summary
}

FOOD-SAFETY KNOWLEDGE, ATTITUDES AND PRACTICES OF

STREET-VENDED FOOD SELLERS IN THE CITY OF KONTUM, 2018

\author{
Giang Nguyen Thi Thu ${ }^{2 *}$, Khai Le Tri ${ }^{1}$, Trung Hoang Chi ${ }^{2}$, \\ Toan Luu Quoc', Tri Hoang Minh ${ }^{2}$ \\ ${ }^{1}$ Health Department of KonTum Province \\ ${ }^{2}$ Food Administration of KonTum Province, \\ ${ }^{3} \mathrm{Ha}$ Noi University of Public Health
}

This study aimed to assess the knowledge, attitudes and practices on food-safety of street-vended food sellers in the city of Kon Tum (2018) in order to provide scientific evidence as a basis for deverloping plan to ensure food safety of street food and to protect consumers' health. Subjects of the study were 160 sellers in 160 street-food vendors. The cross-sectional study was conducted from November 2017 to June 2018. Information was collected through direct interviews and observations. The results showed that: The rate of street-vended food sellers who have (1) good knowledge on food-safety was of $64.4 \%$, (2) positive attitude was of $45.6 \%$, and (3) right practices was of $33.1 \%$. The factors affecting food-safety knowledge were the supervision and inspection of local authorities, and the reaction of sellers $(\mathrm{P}<0.05)$. The factors related to food-safety attitudes were food-safety inspection activities, and food-safety knowledge of the sellers $(\mathrm{P}<0.05)$. The factors affecting food-safety practices were the supervision and inspection of local authorities, and food-safety knowledge of the sellers $(\mathrm{P}<0.05)$.

Keywords: Safe food, street food, knowledge, attitude, practice, KonTum. 